\title{
INNOVATION IN AN INTERNATIONAL THIRD PARTY LOGISTICS FIRM: A STRATEGY-AS-PRACTICE PERSPECTIVE
}

\author{
LIANGUANG CUI* \\ SUSANNE HERTZ* \\ SHONG-IEE IVAN SU** \\ lianguang.cui@ihh.hj.se \\ *Department of Marketing and Logistics, Jönköping International Business School \\ **Supply Chain Lab, School of Business, Soochow University \\ Sweden
}

\begin{abstract}
Logistics firms play an important role in the economy but they have received little attention in strategic management and logistics management literature. This paper intends to fill in this gap by looking a specific strategising process, innovation, at an international third party logistics (TPL) firm. Using strategy as a practice perspective, the paper describes and analyses how innovation emerges and evolves over time. Drawing on an in-depth longitudinal case study of an international TPL firm, this study shows that intra-organisational interactions as well as inter-organisational interactions are essential in the innovation process at logistics firms. The innovation process at logistics firms is complicated and includes both top-down and bottom-up processes. It is vertically decoupled and multidirectional. Innovation at logistics firms emerges as a combination of an ad hoc response to a customer request and a purpose-driven interactive process.
\end{abstract}

\section{INTRODUCTION}

In recent years, the use of third party logistics (TPL) firms is becoming common practice (Lieb, 2008). Through logistics outsourcing, firms can obtain the necessary resources, develop unique assets and achieve superior logistics performance (Sinkovics \& Roath, 2004). Forming relationships with logistics firms is an efficient and effective way to achieve the required service performance without investing heavily in assets and new capabilities (Stank \& Maltz, 1996; Persson \& Virum, 2001). Ashenbaum, Maltz and Rabinovich (2005) show that expenditure on using TPL firms has been growing constantly and is expected to grow in the future.

Logistics firms provide business logistics services to their customers and they are part of several supply chains. Logistics firms' customers are usually subject to change in response to supply chain partners. In turn, logistics firms will have to adapt and react to the change. Logistics firms need to have a deep understanding of their customers' business and actively look into their customers' production and marketing in order to proactively serve them. 
Innovation is a strategic issue for logistics firms to achieve proactivity. Logistics firms can reap first mover advantage and customer loyalty through innovation (Flint, Larsson \& Gammelgaard, 2008). However, there is relatively scant knowledge of innovation in logistics research (Flint, Larsson, Gammelgaard \& Mentzer, 2005). Very few studies address innovation in logistics firms with the result that we know little about how logistics firms innovate.

According to Wagner and Franklin (2008), innovation in the logistics context has a unique nature since it is decentralised rather than centralised. Innovation work and innovative activities are embedded in logistics practitioners' daily life. Thus, the research purpose of this study is to describe and analyse how innovations emerge and evolve over time in logistics firms from a strategising point of view. The strategising perspective is brought into this study since it takes an activity-based view. This article is divided into three parts: the first part highlights the theoretical and methodological issues; in the second part, empirical findings and analysis are presented; and the last part provides research limitations, further research suggestions and conclusions.

\section{LITERATURE REVIEW}

\section{Third party logistics and third party logistics firms}

Knemeyer, Corsi and Murphy (2003) define TPL as a relationship between a shipper and a third party which has more customised offerings, and is characterised as long-term-oriented and mutually beneficial. Bask (2001) regards TPL as relationships between interfaces in the supply chains and TPL providers, where logistics services are offered with the aim of effectiveness and efficiency. Evangelista and Sweeney (2006) treat TPL as activities carried out by a logistics service provider on behalf of a shipper and consisting of at least transportation while other activities can be integrated into service offering.

Berglund (2000) considers TPL as a phenomenon that in simple words can be described as the outsourcing or subcontracting of logistics operations to external service suppliers. He defines a TPL firm as 'an organisation that for external clients manages, controls, and delivers logistical operations' (Berglund, 2000). Berglund's definition emphasises the outsourcing relationship between shipper and external service suppliers. It also defines TPL firms accordingly. Besides, the definition pinpoints the essence of TPL in relatively few words. Thus, this research applies Berglund's definition of a TPL firm and defines a TPL firm as a logistics company that is external and provides logistics services to the user company.

\section{Innovation}

Undoubtedly, innovation plays an essential role in the success of most firms. However, innovation is largely neglected in logistics research (Flint et al., 2005). According to Rogers (1995), innovation can be broadly defined as an idea, practice, or object that is regarded 
as new by an individual or an organisation. In logistics management literature, innovation is defined as any logistics-related service that is seen as new and helpful to a particular focal audience (Flint et al., 2005). In contrast, Wagner and Busse (2008) define innovation as 'a subjective novelty which is the result of a conscious management process and which aims at economic exploitation'. Wagner and Busse's (2008) definition and Flint et al.'s (2005) definition are consistent on one point. In the logistics context, innovation does not need to be new to the world or new to the market. As long as it is new to a specific client, it can be regarded as innovation. However, Wagner and Busse's (2008) definition complements Flint et al.'s (2005) definition by pointing out the essence that innovation at logistics firms is an outcome of a conscious management process. Further, it is highlighted that the purpose of innovation at logistics firms is to exploit economic benefits. Therefore, this article adopts Wagner and Busse's definition and supports the idea that logistics firms need to regard imitation as innovation (Wagner \& Busse, 2008).

Innovation is often assumed to be a unidirectional process and is treated as a vertically coupled, intra-organisational process (Benner \& Tushman, 2003; Markman, Gianiodis \& Phan, 2009). However, due to the nature of logistics services, innovation in the logistics sector often arises not because of a formal plan or process but as an ad hoc response to a customer request (Wagner and Franklin, 2008). Besides, Wagner (2008) argues that logistics innovation is a bottom-up process instead of a top-down one. In order to have a better understanding of the innovation process at logistics firms, logistics researchers need to go deeper into the process and find out what is happening over time. Therefore, it is necessary to investigate the daily activities and practices of logistics practitioners.

\section{Strategy as practice}

The point of departure of this study is the emerging strategy as practice perspective (Johnson, Melin \& Whittington 2003; Whittington, 2003; Jarzabkowski, 2005). The approach is relevant for this study since it views strategising 'as a socially accomplished, situated activity arising from the actions and interactions of multiple level actors' (Jarzabkowski, 2005). The logistics industry is a practice-oriented industry. Logistics practitioners are tied up with daily practical activities. However, little is written about what logistics practitioners do over time. Adopting the strategy-as-practice approach can help to depict the daily activities of logistics practitioners.

This study looks at the actions and interactions of logistics practitioners over time in an international TPL firm. TPL firms are characterised by a network of representative offices and daughter companies and a plethora of organisational levels. The complicated organisational settings indicate that strategising is seldom the responsibility of one group of managers representing a single organisational level. These firms usually have multiple localised entities engaged in the strategy process (Paroutis \& Pettigrew, 2007). Their customers are 
often multinational companies operating in different geographical markets. In such settings, strategising is constituted by inter-organisational interactions with external customers as well as intra-organisational interactions among multiple entities from various organisational levels. Therefore, it is necessary to examine managers representing multiple levels across firms. Nordqvist and Melin (2008) argue that 'this shift in the level of analysis allows us to examine in greater detail what characterises the work and performance of individual practitioners'.

Several scholars have attempted to study the action and interaction of strategists across levels. Regnér (2003) studied the managerial actions at the centre and periphery of four multinational organisations. Floyd and Lane (2000) have investigated the various roles of top, middle and operational level managers in organisations. Paroutis and Pettigrew (2007) take a further step and study the actions and interactions of strategy teams over time in a multi-business firm. They investigate the nature of interactions over time between strategy teams located at the corporate centre and the business units. While these studies contribute to our understanding of actions and interactions across levels within a firm, they pay little attention to inter-organisational interactions (Jarzabkowski \& Spee, 2009).

This article adopts Jarzabkowski, Balogun and Seidl's (2007) definition of strategy as 'a situated practice that they draw upon in accomplishing that activity'. According to Johnson et al. (2007) and Whittington (2006), the strategy-as-practice approach has concentrated its broad research parameters on studying practitioners, practices, praxis and profession. Johnson et al. (2003) suggest moving to a greater emphasis on how people, rather than the firm, can exert influences on strategic outcomes. The strategy-as-practice approach favours a set of change events from a firm level of analysis rather than have its focus set on them, as many process studies tend to do (Jarzabkowski \& Spee, 2009). Following this approach, our study investigates the activities of logistics practitioners and contributes to our understanding of what logistics practitioners do during the strategy process.

Strategy as practice is concerned with what people do and focuses on strategy practitioners (Johnson, et al. 2007). However, according to Jarzabkowski and Spee (2009), the existing literature provides broad definitions of who might be considered a strategy practitioner. Jarzabkowski and Whittington (2008) treat strategy practitioners as those directly involved in strategy-making and those with indirect influence. Whittington (2007) regards strategy practitioners as a diverse set of managers at the top and below, and actors both internal and external to the organisation. Jarzabkowski et al. (2007) and Whittington, Jarzabkowski, Mayer, Mounoud, Nahapiet and Rouleau (2003) claim that strategy practitioners are not only from inside the organisation but also outside the organisational boundary. The wide perspective on strategy practitioners helps to define logistics practitioners. In logistics management literature, the concept of 'logistics practitioner' is not clearly defined while 
it usually means logistics managers at the buying company or managers working in the logistics firms. This study defines logistics practitioners as managers at various levels in the logistics firms, logistics managers at buying firms and logistics consultants, gurus and regulators.

\section{RESEARCH QUESTION DEVELOPMENT}

The literature review reveals that researchers tend to regard innovation as a unidirectional process. Innovation is often treated either as a top-down process or a bottom-up process. However, very few studies have pointed out the fact that logistics firms are complex business service providers. Innovation at logistics firms is embedded in logistics practitioners' daily activities. It is an outcome of logistics practitioners' strategising practices. In order to describe and analyse the innovation process at logistics firms it is necessary to investigate the practices carried out by logistics practitioners. Therefore, the research question of this study is: What daily activities and practices do logistics practitioners conduct to generate innovation?

\section{RESEARCH STRATEGY}

This study intends to depict the practice of logistics practitioners at an international logistics firm. It is a natural way to follow the qualitative approach. This research has carried out an in-depth longitudinal case study of an international logistics firm. Several motivations have driven the choice of a qualitative case study approach. First, the review of existing literature underpins the weak understanding of the innovation process in a logistics environment, confirming the need for more theoretical development. A case study can help logistics researchers to generate new concepts and theories with a loose theory base (Arlbjorn \& Halldorsson, 2002). Second, according to Aastrup and Halldorsson (2008), a case study is able to reach a causal depth required for revealing the real domain of logistics activities and performance as well as reveal the working of mechanisms in loosely coupled structures showing open systems characteristics. Third, this research deals with problems that are practical in nature. A case study approach allows researchers to gather first-hand information to develop knowledge and gain relevance (Naslund, 2002).

The research reported on here is based on empirical findings obtained through a single case study with empirical data collection based on semi-structured interviews, observations and documentation with an international TPL firm in different regions. This research follows the process suggested by Ellram (1996). A case company has been chosen according to purposeful sampling. The case company was selected based on its market reputation in logistics innovation, openness to share experience and willingness to participate in the research. The researchers approached the president of the case company in order to obtain 
access and initiate the research. Since the researchers did not know who was involved in the innovation process, interview participants were selected based on the snowball effect. An interview guideline was first developed and sent to the interviewee prior to the interview in order to facilitate the interview process. The guideline provided interviewees with a clear understanding of the background and purpose of the research. It included key questions and interview guidelines. In order to discover as much information as possible, questions were open-ended and broad before delving into the topic. Each interview took 1.5 to 3.0 hours to complete. In total, 15 interviews were conducted. A list of interviewees is provided in Appendix A. All of the interviews were recorded and transcribed. In order to get a deeper understanding, the researchers tried to conduct the interviews in the interviewee's native language. Originally, only three interviews were conducted in English. The rest of the interviews were conducted in Mandarin. Those interview transcripts were translated into English and sent back to the interviewees for comments. The purpose was to avoid mistakes and misunderstandings. All comments have been taken into consideration and all transcripts have been corrected accordingly.

In addition, the researchers visited several operation sites of the case company in China and the United States of America (US). The purpose was to observe logistics practitioners' daily activities. Detailed notes were made during their observations. Furthermore, the researchers gained access to company documents such as brochures, presentation material, annual reports and marketing material.

The empirical data was analysed according to the coding processes (Miles \& Huberman, 1994; Ellram, 1996). The coding process focused on activities of logistics practitioners. The researchers first conducted open coding to break down data in order to analyse, conceptualise and develop categories. Then the researchers went on with axial coding and made connections among categories developed in open coding. Further, a central category of the analysis was selected and related to other categories (Strauss \& Corbin, 1990).

\section{CASE COMPANY DESCRIPTION}

The case company, Dimerco Express Group (DEG), which is listed on the Taiwanese stock market, was established in 1971. The president of DEG is also the owner. DEG started as an air freight forwarder and has developed into a TPL firm specialised in Asia Pacific, Greater China and the US offering logistics services to firms in many industries. Most of DEG's customers have global operations, making it necessary for the company to provide a global network of services. In Mainland China and the US, DEG's major markets, the company operates fully owned subsidiaries and many branch offices. DEG has formed alliances with other firms in continents not strategically critical to the firm. In South East Asia, due to highly diversified cultures and local regulations, DEG has established several joint ventures 
with local players, such as in India and Indonesia. In contrast, DEG's business in Europe is small. Thus, DEG has formed alliances with several European logistics firms in order to cover the region.

Many DEG customers are from the electronics industry and they use an air freight service because of the characteristics of the industry. Due to low costs, comparative advantages and size of the local market, various electronics manufacturers have established their operations in mainland China. However, in their early moves during the $2000-2005$ period, the development of shipping capacities in mainland China lagged behind, creating a bottleneck for logistics operations, especially in air transportation. Thus, queuing in the airport for air freight space is not unusual. Based on its e-Chain System, the platform for communication, operation and service, DEG cooperates with shipping companies, developing new service products for its customers. It offers an affordable combined transport service to its customers. Instead of waiting in the airport without knowing the time of departure, DEG helps customers to move the product from the departure city in mainland China either via Hong Kong or Taipei. These two cities have good international flight connections so customers can always have their products delivered to the destination in time with less economic expenditure. Even though the lead time is longer these alternative routes have decreased the arrival time uncertainty at the destination. In addition, in the low season, customers can choose this type of service to save money and still apply the just-in-time (JIT) principle. Supply of airlines' and/or ocean liners' capacity in mainland China nowadays has no bottlenecks. With experience and new infrastructure, transit via Taipei has become a ready service option for customers. Transit via Hong Kong is, due to logistics advantages and the capacity issue, used mostly for shipments with Southern China origins and destinations.

Apart from developing new service products based on its logistics service platform driven by customers, DEG also innovates in other areas such as customs clearance services and air cargo insurance selection. Customers exporting products to mainland China need to declare import customs tariffs. Due to the fact that the tariff system in mainland China is quite complex, customers usually do not know how to handle customs clearance procedures. Therefore, DEG has obtained relevant certificates of tariff declaration and encourages its employees to get licences for customs clearance. As a result, DEG provides different modes of import logistics services and/or consultancy by leveraging its existing business knowledge and practice in mainland China, its knowledge of international logistics management and mainland China customs regulations to help customers apply accurate import tariff and/or enjoy deferred duty assessment. Another example is a consulting service for buying cargo insurance. Drawing on its expertise in air transport, DEG is able to help its customers to choose the most appropriate cargo insurance product with the best price from the right insurance company. 
As far as the organisation is concerned, DEG puts great emphasis on education and development of employees. Employees often start with a single function entry-level position, and then change to different functions and positions to move up the corporate ladder. By having experience in different functions and positions, employees can obtain cross-functional knowledge and enhance their logistics skills and ability. DEG has instituted a system of rotating positions to guarantee that the right people will be put into the right position. In addition, DEG provides a comprehensive internal training programme such as skills development and management training to develop its employees. DEG has programmes to develop and retain human capital for business expansion in mainland China and other global locations.

DEG organises annual meetings and invites management teams from all subsidiaries and branches in the world to attend. Latest innovations and new service developments are shared in the annual meeting, and management teams from different areas can learn from success stories and experiences to further develop better business systems in their own areas. During these meetings, professors from academic institutions are invited to deliver speeches so employees can obtain up-to-date knowledge on logistics and supply chain management. With a tailor-made training system to develop executives and frontline employees, DEG people can better understand customer needs and discover their unmet needs, and use them as inputs for their innovation initiatives. Recently, DEG set up a focus group with the mission of cultivating business innovation. The focus group brings together highly efficient employees and some middle managers. The idea for having such a focus group is to encourage innovation from the bottom up instead of from the top down.

\section{EMPIRICAL FINDINGS}

\section{Practices and activities of logistics practitioners}

The coding process has generated eight categories in the practices of logistics practitioners. Table I presents the practices and activities carried out by logistics practitioners during the innovation process. The eight categories contain focusing, interacting, analysing, idea generating, justifying, developing, transferring, and creating atmosphere. Appendix B offers additional empirical insights into the categories of practice carried out by logistics practitioners. 
Table I: Practices and activities carried out by logistics practitioners during strategising in the multinational logistics firm

\begin{tabular}{|c|c|}
\hline Practice & Activities comprising the practices \\
\hline Focusing & $\begin{array}{l}\text { Focus on certain market segments and concentrate on specific groups of } \\
\text { customers. }\end{array}$ \\
\hline Interacting & $\begin{array}{l}\text { Share information among practitioners, customers, regional offices, customers' } \\
\text { suppliers and customers. Explore and understand customers' requirements and } \\
\text { demands. }\end{array}$ \\
\hline Analysing & Develop reports and analysis created by logistics practitioners. \\
\hline Idea generating & $\begin{array}{l}\text { Based on customers' requirements and company capabilities, logistics } \\
\text { practitioners come up with new ideas in order to serve customers. }\end{array}$ \\
\hline Justifying & Justify the investment and investigate the costs and benefits. \\
\hline Developing & Develop new ideas and new service offerings. \\
\hline Transferring & $\begin{array}{l}\text { When new ideas are developed into new offerings and successfully implemented, } \\
\text { share them with the other regional offices. }\end{array}$ \\
\hline Creating atmosphere & $\begin{array}{l}\text { Head office and the regional offices do activities aimed at making a positive } \\
\text { environment to encourage change and new ideas. }\end{array}$ \\
\hline
\end{tabular}

Focusing concerns the strategic focus of a firm to generate innovation. DEG concentrates on high-value and fast-moving products and focuses especially on customers in the electronics industry. The head office of DEG clarifies its focused market segments and emphasises the core business to its regional offices. All regional offices need to obtain knowledge and information about the customers on whom they are focusing. Customers outside the core business area will not be considered for innovation.

Interacting refers to the most common day-to-day activities conducted by logistics practitioners. Interacting occurs when logistics practitioners communicate with customers regarding daily operations. It also occurs when different teams within the same regional office communicate with each other to share information and knowledge. In addition, interacting occurs among regional offices. Dimerco's customers are mainly multi-national firms and they have operations in various geographical locations. Thus, different regional offices need to communicate the operational information concerning the same customer. Furthermore, they need to communicate with customers' local suppliers and customers regarding daily arrangements. The purpose of interaction on all levels is to have a holistic view of the customers' supply chains. In turn, DEG can identify areas for improvement. Another issue is that governmental authorities in Far East Asia often change their policies and regulations. DEG needs to communicate with them in order to update and change its operation accordingly. 
Interacting also refers to activities conducted by logistics practitioners to explore and understand customers' requirements and demands. Logistics firms usually have diversified customers. Customers operate in various industries and they have different needs. With regard to multi-national firms, operations in different geographical locations demand different services. For instance, in mainland China many firms set up their manufacturing facilities and source locally. As a result, warehousing, pick-and-pack as well as freightforwarding services are needed. In the US, firms demand more distribution and delivery services since it is a consumer market. Logistics practitioners need to constantly interact with customers in order to identify the needs of each and every customer based on industry specifics and operating environment.

Analysing concerns the analysis of reports and documents created by logistics practitioners. In order to serve the clients proactively, a deep understanding of customers' businesses is required. Therefore, logistics practitioners need to take multiple factors into consideration when they analyse the reports and documents. First, they need to analyse customers' products and their characteristics. Second, they are obliged to analyse customers' operation set-up and their positions in the overall supply chain. Third, they need to analyse the market trend as well as the changing rules and regulations. Fourth, they need to analyse competitors and new service packages offered in the logistics service market. All analysis and reports are shared locally and globally through regional meetings, budget meetings and annual meetings. As a result, logistics practitioners can build a solid base to further develop new ideas.

Idea generating occurs when there is a gap between customer needs and service offerings. Based on customers' requirements and the company's capabilities, logistics practitioners come up with new ideas in order to serve customers more successfully. New idea generation refers to new daily operation routines, the adoption and application of new technology, and new service offering packages. New ideas can also emerge from the customer side. Customers can present their unique ideas while logistics practitioners would follow the idea and further develop it. A new idea can come from customers and their suppliers. Through interaction with customers, customers' suppliers and customers' customers, logistics practitioners can understand customers' supply chains better and develop appropriate ideas.

Justifying refers to activities taken by regional offices and the head office. Not all of the new ideas can be further developed. New ideas are analysed in terms of how difficult it is to turn them into practice and total investment for DEG. The purpose is to select the most reasonable and realistic ideas. Logistics practitioners at the regional offices of DEG will balance the total costs and benefits of the new ideas. If the new idea is justified, it will be proposed to the head office. The head office will further consider the resources required 
and the potential to leverage. If it is approved by the head office of DEG, the new idea will receive resources for further development. Otherwise, it will be turned down.

Developing concerns the development of new ideas and new service offerings. Turning new ideas into reality requires time and effort. It also requires support from the headquarters and other regional offices. Further, it demands other functional departments, such as IT and finance, to assist with the development. Developing and implementing new service offerings often indicates a new operation process and new practice routines. Some members might be reluctant to change since they are already used to the current practice and they might not fully comprehend the advantages of new practice. Overcoming the barriers listed above is also part of developing the new ideas and new service offerings.

Transferring occurs when new ideas are developed into new service offerings and successfully implemented. Then the successful case will be transferred to other regional offices. Responsible logistics practitioners present their cases in regional meetings as well as annual meetings. Important knowledge and experience are shared. Interested regional offices would receive help from responsible logistics practitioners to implement the new service offering.

Creating atmosphere refers to activities taken by both the head office and regional offices of a firm aimed at making a positive environment to encourage change and new ideas. On the one hand, managers in the head office on the top level encourage an innovative corporate culture centrally. Then, the innovative corporate culture is initiated at regional office level by the head office. On the other hand, managers in the regional offices maintain the innovative culture and attempt to encourage co-workers to be service-minded and react proactively to customers' demands. They also try to change daily operation routines in order to give more freedom to co-workers. Thus, co-workers can generate new ideas and come up with new solutions.

\section{DISCUSSION}

Based on the empirical findings, several points need to be highlighted and discussed. First, logistics practitioners at DEG are constantly interacting with each other across multiple levels. Managers at the head office are responsible for deciding on market segments in which to innovate. They communicate the strategic decisions with managers in different regional offices through annual meetings and budget meetings. Managers in different regional offices also need to interact with each other in order to share information about the same customer. Thus, they can obtain a holistic view of customers' global operations and a deeper understanding of customers' supply chains. Based on the in-depth knowledge of customers' business, managers at DEG can identify potential areas for improvement and generate new ideas accordingly. 
Logistics practitioners at DEG do not only interact with each other internally, but also interact continuously with customers and customers' partners. They actively communicate with the customers through phone calls, e-mails and company visits in order to identify customer requirements. However, customers' needs and requirements are often dependent on their own customers and suppliers (Hakansson \& Snehota, 1995). Therefore, it is necessary for logistics practitioners to interact and communicate with customers' customers and suppliers. The whole interaction process is organised according to customers' needs and is dependent on the customers and their supply chains. In addition, when DEG's customers develop or change in different geographical markets, DEG has to react and adopt in order to serve its customers more actively. Through interactions with customers' partners and analysis of documents, customers' requirements can be better identified. Hence, it is argued that intra-organisational as well as inter-organisational interactions are essential in the innovation process at logistics firms.

Second, in DEG's case, the head office decides its focused market segments and transfers the message to its regional offices. All regional offices receive the message and concentrate on focused customers. This is a top-down process. On the other hand, new ideas are generated by logistics practitioners at regional offices. As long as the idea is justified and approved, it is first developed regionally and transferred through head office. It indicates that innovation and new service offerings emerge from regional offices and evolve both regionally and centrally. It is a bottom-up process instead of top-down. According to Wagner (2008) and Markman et al. (2009), most of the existing research and practice tries to treat innovation as a vertically coupled process. However, it does not seem valid in the logistics service industry. It is proposed that the innovation process at logistics firms is a complicated process including both top-down and bottom-up processes. Furthermore, this point partly corroborates Regnér's (2003) study and indicates that strategy-making in the periphery is inductive. But the empirical data has not shown any support for the point that strategy-making in the centre is more deductive. It is suggested that further investigations be done of the strategy-making process at head office.

Third, the innovation process at DEG has a unique characteristic. The head office of DEG starts the process by identifying some focused customers. Then the strategic decisions are delivered down to the regional offices. The regional offices come up with new ideas and bring them up to the head office. The head office justifies the new ideas and allocates resources down to the regional offices. The regional offices develop the new ideas and generate innovative outcomes. All innovative outcomes are transferred to the whole group through the head office. Meanwhile, DEG's service offerings are part of customer's business. Based on the in-depth knowledge of customers' supply chain operations, managers at DEG need to come up with appropriate new ideas and develop suitable solutions for its customers. Further, logistics services are complex industrial services, combining complicated 
technology, service equipments and service processes. As a logistics service provider, DEG also needs to deal with its own suppliers when it innovates. Therefore, it is not valid to assume that innovation is a unidirectional process at logistics firms (Benner et al., 2003). It is proposed that innovation in a logistics context is not unidirectional nor bidirectional but multidirectional. Logistics practitioners, not only within the logistics firms and buying firms, but also those involved in external ones, will have to work together in order to turn their innovative ideas into reality.

Fourth, in DEG's case, its innovative offerings are reactive innovations to customers' requirements. The empirical findings partly support Wagner et al. (2008) that innovation in logistics firms often arises as an ad hoc response to a customer request. However, DEG actively interacts with its customers to identify unmet needs and develop new services. DEG also proactively analyses customers' businesses and generates new ideas. When an innovative outcome is successfully launched, DEG promptly transfers it to the whole group. Innovations at DEG emerge and evolve over time through this purpose-driven process. Thus, it is proposed that innovation in international TPL firms emerges as a combination of an ad hoc response to a customer request and a purpose-driven process.

Finally, it is suggested that the practices of logistics practitioners in an international TPL firm could have either a positive or negative impact on organisational outcomes. A positive atmosphere could encourage logistics practitioners to have a service-minded attitude and try to interact with customers proactively instead of reactively. As a result, logistics practitioners would actively search for new solutions. A positive atmosphere helps logistics practitioners to better identify customers' needs and generate a more thorough analysis of customers' situations and requirements. In turn, new ideas could be fostered and developed into new offerings and new solutions. It will close the gap between customers' changing needs and a firm's service offerings. Transferring the knowledge and new service package to other regional offices would help the overall firm to serve the customer better in different geographical markets. Through constant improvements, customers would be satisfied and would tend to maintain the relationship (Wallenburg, 2009). Innovative service offerings might be new to the market or new to a specific group of customers and might attract new customers.

\section{LIMITATION AND FUTURE RESEARCH}

There are a number of limitations within the study and findings. First, empirical data has only been collected through interviews and documentation. Therefore, the findings of the study are mainly derived from the interview data and related documents. There is no direct participation or observation of strategy meetings. It hinders the researchers from obtaining in-depth insights. It is beneficial to gain access and observe some strategy meetings such 
as a budget meeting, annual meeting and regional meeting. Second, the study focused on only one firm. Looking into more international logistics firms could be useful in generating findings. The authors might have gained additional insights had they compared their findings with those of other logistics firms. Future studies could try to investigate more logistics firms in different countries and conduct comparative studies between different types of international TPL firms in terms of corporate governance and culture.

\section{CONCLUSION}

This study has empirically described and analysed the innovation process at an international TPL firm using a strategy-as-practice perspective. The practices of logistics practitioners in the innovation process have been identified. They included focusing, interacting, analysing, idea generating, justifying, developing, transferring and creating atmosphere. These practices are useful for guiding practitioners to innovate in the logistics industry.

This study also provides a unique revelation of how innovations emerge and evolve over time. It is proposed that intra-organisational interactions as well as inter-organisational interactions are essential in the innovation process at logistics firms. The innovation process at logistics firms is a complicated process including both top-down and bottomup processes. It is vertically decoupled and multidirectional. Innovation at logistics firms emerges as a combination of an ad hoc response to a customer request and a purposedriven interactive process. 


\section{REFERENCES}

Aastrup, J. \& Halldorsson, A. 2008. Epistemological role of case studies in logistics - a critical realist perspective. International Journal of Physical Distribution \& Logistics Management, 38(10): 746-63.

Arlbjorn, J. S. \& Halldorsson, A. 2002. Logistics knowledge creation: Reflections on content, context and processes. International Journal of Physical Distribution \& Logistics Management, 32(1): 22-40.

Ashenbaum, B., Maltz, A. \& Rabinovich, E. 2005. Studies of trends in third-party logistics usage: What can we conclude? Transportation Journal, 44(3): 39-50.

Bask, H. 2001. Relationships among TPL providers and members of supply chains - A strategic perspective. Journal of Business and Industrial Marketing, 16(6): 470-86.

Benner, M. \& Tushman, M. 2003. Exploitation, exploration, and process management: The productivity dilemma revisited. Academy of Management Review, 28: 238-56.

Berglund, M. 2000. Strategic positioning of the emerging third-party logistics providers. Dissertation, Department of Management and Economics, Linköping University, Linköping.

Ellram, L. 1996. The use of the case study method in logistics research. Journal of Business Logistics, 17(2): 191-205.

Evangelista, P. \& Sweeney, E. 2006. Technology usage in the supply chain: the case of small 3PLs. International Journal of Logistics Management, 17(1): 55-74.

Flint, D., Larsson, E., Gammelgaard, B. \& Mentzer, J. 2005. Logistics innovation: A customer value-oriented social process. Journal of Business Logistics, 26(1): 113-46.

Flint, D., Larsson, E. \& Gammelgaard, B. 2008. Exploring processes for customer value insights, supply chain learning and innovation: An international study. Journal of Business Logistics, 29(1): 257-281.

Floyd, S. \& Lane, P. 2000. Strategizing throughout the organization: Managing role conflict in strategic renewal. Academy of Management Review, 25(1): 154-77.

Hakansson, H. \& Snehota, I. 1995. Developing Relationships in Business Networks, London: Routledge. 
Jarzabkowski, P. 2005. Strategy as practice: An activity-based view, London: Sage.

Jarzabkowski, P., Balogun, J. \& Seidl, D. 2007. Strategizing: The challenges of a practice perspective. Human Relations, 60: 5-27.

Jarzabkowski, P. \& Spee, A. 2009. Strategy-as-practice: A review and future directions for the field. International Journal of Management Reviews, 11(1): 69-95.

Jarzabkowski, P. \& Whittington, R. 2008. Hard to disagree, mostly. Organization Studies, 28: 1639-65.

Johnson, G., Langley, A., Melin, L. \& Whittington, R. 2007. Strategy as practice: Research directions and resources, Cambridge: Cambridge University Press.

Johnson, G., Melin, L. \& Whittington, R. 2003. Micro strategy and strategizing: Towards an activity-based view. Journal of Management Studies, 40(1): 23-55.

Knemeyer, M., Corsi, M. \& Murphy, R. 2003. Logistics outsourcing relationships: Customer perspectives. Journal of Business Logistics, 24(1):77-109.

Lieb, R. 2008. The North American third-party logistics industry in 2007: The provider CEO perspective. Transportation Journal, 47(2): 39-53.

Markman, G., Gianiodis, P. \& Phan, P. 2009. Supply-side innovation and technology commercialization. Journal of Management Studies, 46(4): 625-49.

Miles, M. \& Huberman, M. 1994. Qualitative data analysis, Thousand Oaks: Sage Publications.

Naslund, D. 2002. Logistics needs qualitative research - especially action research. International Journal of Physical Distribution \& Logistics Management, 32(5): 321-38.

Nordqvist, M. \& Melin, L. 2008. Strategic planning champions: Social craftspersons, artful interpreters and known strangers. Long Range Planning, 41: 326-44.

Paroutis, S. \& Pettigrew, A. 2007. Strategizing in the multi-business firm: Strategy teams at multiple levels and over time. Human Relations, 60(1): 99-135.

Persson, G. \& Virum, H. 2001. Growth strategies for logistics service providers: A case study. International Journal of Logistics Management, 12(1): 53-64.

Regnér, P. 2003. Strategy creation in the periphery: Inductive versus deductive strategy making. Journal of Management Studies, 40(1): 57-82. 
Rogers, E. 1995. Diffusion of innovations, New York: Free Press.

Stank, T. \& Maltz, A. 1996. Some propositions on third party choice: domestic vs. international logistics providers. Journal of Marketing Theory and Practice, 4(2): 45-54

Sinkovics, R. \& Roath, A. 2004. Strategic orientation, capabilities, and performance in manufacturer - 3pl relationships. Journal of Business Logistics, 25(2): 43-64.

Strauss, A. \& Corbin, J. 1990. Basics of qualitative research: Grounded theory procedures and techniques, London: Sage.

Wagner, S. 2008. Innovation management in the German transportation industry. Journal of Business Logistics, 29(2): 215-31.

Wagner, S. \& Busse, C. 2008. Managing innovation at logistics service providers - an introduction, in Wagner, S. \& Busse, C. (Eds), Managing Innovation - the New Competitive Edge for Logistics Service Providers, Berne: Haupt.

Wagner, S. \& Franklin, J. 2008. Why Lsps don't leverage innovations. Supply Chain Quarterly, 2(4): 66-71.

Wallenburg, C. 2009. Innovation in logistics outsourcing relationships: Proactive improvement by logistics service providers as a driver of customer loyalty. Journal of Supply Chain Management, 45(2): 75-93.

Whittington, R. 2003. The work of strategizing and organizing: For a practice perspective. Strategic Organization, 1: 119-27.

Whittington, R. 2006. Completing the practice turn in strategy research. Organization Studies, 27(5): 614-34.

Whittington, R. 2007. Strategy practice and strategy process: Family differences and the sociological eye. Organization Studies, 28: 1575-86.

Whittington, R., Jarzabkowski, P., Mayer, M., Mounoud, E., Nahapiet, J. \& Rouleau, L. 2003. Taking strategy seriously: Responsibility and reform for an important social practice. Journal of Management Inquiry, 12: 396-409. 


\section{APPENDIX A}

\begin{tabular}{|c|l|l|}
\hline No. & Title & Location \\
\hline 1 & President & Head Office, Taipei \\
\hline 2 & Corporate Executive Vice President & Head Office, Taipei \\
\hline 3 & General Manger & Head Office, Taipei \\
\hline 4 & Corporate Marketing Manager & Head Office, Taipei \\
\hline 5 & Director, North China & Beijing Office, Beijing \\
\hline 6 & Assistant General Manager, North China & Tianjin Office, Tianjin \\
\hline 7 & MNC Team & Tianjin Office, Tianjin \\
\hline 8 & Assistant Manager & Beijing Airport, Beijing \\
\hline 9 & Manager, Import Department & Beijing Airport, Beijing \\
\hline 10 & Manager & Beijing Airport, Beijing \\
\hline 11 & Export Manager & Beijing Airport, Beijing \\
\hline 12 & In-house representative & Tianjin Airport, Tianjin \\
\hline 13 & General Manager & New York Office, New York \\
\hline 14 & Assistant General Manager & New York Office, New York \\
\hline 15 & Marketing Manager, North America Region & Chicago Office, Chicago \\
\hline
\end{tabular}

\section{APPENDIX B}

\begin{tabular}{|l|l|}
\hline Practice & Extracts from the interviews at DEG \\
\hline Focusing & $\begin{array}{l}\text { "If a firm doesn't know its developing and growth direction, innovation is meaningless." } \\
\text { "Who are our target customers? We need a clear answer. It is all about target market. We } \\
\text { pay attention to it and develop it." } \\
\text { (Corporate Executive Vice President) }\end{array}$ \\
\hline Interacting & $\begin{array}{l}\text { "We need to have a close relationship with our customers in order to identify their needs." } \\
\text { "We keep in touch with our headquarter every day by telephone and our CEO visits us } \\
\text { (Director, North China) } \\
\text { "We used to have Chinese colleagues. We discussed with them in North America Regional } \\
\text { meeting, and then American colleagues will contact a certain person for information." } \\
\text { (Corporate Marketing Manager) } \\
\text { "Sales people start talking with customers to identify needs. Our marketing and operation } \\
\text { team will follow up and further communicate with customers." } \\
\text { (General Manager, North America) } \\
\text { "When we communicate with our customers, we need to consider their background and } \\
\text { function. Then we can select the right language in order to communicate with each other." } \\
\text { (MNC team, Tianjin Office) }\end{array}$ \\
\hline
\end{tabular}




\begin{tabular}{|c|c|}
\hline & $\begin{array}{l}\text { "We need to have a close relationship with our customers in order to identify their needs. } \\
\text { Our service is like the one offered by an assistant. Our employees will be sent to the } \\
\text { customers' offices and help them to develop a better logistics solution together. During } \\
\text { these processes, the customers will know our services better and we can provide other } \\
\text { services to them at the same time. Our employees can help the customers to find out their } \\
\text { problems in order to get a better solution to their needs." } \\
\text { "We focus on our major customers and go through their supply chains. We look at their } \\
\text { suppliers and customers in order to have a broader picture of their supply chain. It helps us } \\
\text { to identify our customer's needs better." } \\
\text { (Director, North China) } \\
\text { "The key issue is to follow the market and grasp the essential needs of the market." } \\
\text { (Assistant Manager, Beijing Airport Branch) }\end{array}$ \\
\hline ing & $\begin{array}{l}\text { "Some of our customers didn't care about cost so much. They need on-time delivery. Some } \\
\text { of our customers are cost-oriented. They always want cheaper prices. We need to analyse } \\
\text { this information." } \\
\text { (Corporate Marketing Manager) } \\
\text { "We need to analyse the market and external environment. We try to figure out the market } \\
\text { trend. Then we can react and change." } \\
\text { (Director, North China) } \\
\text { "Our marketing department conducts research to find out what is being exported from the } \\
\text { country, what is coming into the country. Then we focus on these industries because we } \\
\text { know that is the future." } \\
\text { (Assistant General Manager, North America) }\end{array}$ \\
\hline & $\begin{array}{l}\text { "When there is a gap between our service offering and customer requirement, someone } \\
\text { has to design a new service idea and test it. Then we need to make it into a visible } \\
\text { product." } \\
\text { (General Manager, North America) } \\
\text { "Usually, the freight travels from P to P or D to D. It is usually direct flight. However, it is } \\
\text { different in the peak season. For instance, in last two years, the supply and the demand } \\
\text { are unbalanced in Shanghai. Since air freight relates to rights of flight, you have to get } \\
\text { the proof from the government in order to let your flight take off and land. Shanghai } \\
\text { used to be an intensive city, the supply from surrounding cities is really huge. As a result, } \\
\text { the capacity of the air flight is not enough. The freight or passenger flight often cannot } \\
\text { take off on time. We make a suggestion to our customers that you can choose another } \\
\text { solution instead of waiting. Since Taiwan air flights have bigger capacity, you can choose } \\
\text { to transfer from Taiwan instead of direct flight. You can choose to transfer your cargo by } \\
\text { sea from Shanghai to Kaohsiung or Keelung port in Taiwan and then fly your products from } \\
\text { Taoyuan airport in Taipei to your destination. Choosing combined transport in order to } \\
\text { ship to Europe and America feels a little bit strange. But at least you can move out your } \\
\text { cargo. Transport the goods from Shanghai to Taiwan by sea and fly from Taipei. This is an } \\
\text { opportunity that we provide for our customers. It also protects our customers' rights. For } \\
\text { me, direct freight is not the only solution." } \\
\text { (Corporate Marketing Manager) }\end{array}$ \\
\hline Justifying & $\begin{array}{l}\text { "There are a lot of concerns when we try to innovate. One of them is justification. Any new } \\
\text { idea or new service will take people to consider investment. Is the investment justified? } \\
\text { What are the costs and benefits?" } \\
\text { (General manager, North America) }\end{array}$ \\
\hline
\end{tabular}




\begin{tabular}{|c|c|}
\hline & $\begin{array}{l}\text { "Some of the ideas are not realistic. Some of them are not consistent with our corporate } \\
\text { strategy. Some of them are hard to turn into practice. Then we need to turn it down." } \\
\text { (General Manager) }\end{array}$ \\
\hline Developing & $\begin{array}{l}\text { "There is a lot of information on our website. We can see many moving messages. We } \\
\text { keep developing our website in order to create a better interface between customers and } \\
\text { us." } \\
\text { (Corporate Executive Vice President) } \\
\text { "We constantly develop our service products and offer more varieties. For instance, } \\
\text { according to customers' requirements, we can provide various kinds of combined } \\
\text { transport. We can also add insurance and custom clearance into the service package. Then } \\
\text { we customise the package in order to fit customer's operation." } \\
\text { (Director, North China) } \\
\text { "We can look at our customers' process and analyse it. Based on our professional } \\
\text { knowledge, we can re-engineer the complicated process and modify certain procedures." } \\
\text { (Assistant General Manger, North China) }\end{array}$ \\
\hline Tra! & $\begin{array}{l}\text { "The process of adding experience is really crucial. We often talk about using what } \\
\text { you have learnt. This is the process of transferring learning to your own experience and } \\
\text { knowledge base." } \\
\text { (General manager, North America) } \\
\text { "We have a very good system to rotate people so knowledge and experience can be } \\
\text { transferred. For instance, one of our colleagues in the Beijing office moved to the US and } \\
\text { stayed there for three years. He has introduced the situation of Chinese market to our US } \\
\text { colleagues. He has also learnt the knowledge from our US colleagues. When he comes } \\
\text { back, he can transfer that knowledge to our colleagues in Beijing." } \\
\text { (Director, North China) } \\
\text { "We have learnt from customer A and developed a new model. Then we can apply the } \\
\text { model to customer B and customer C. It really works and generates positive results." } \\
\text { (Corporate Marketing Manager) }\end{array}$ \\
\hline $\begin{array}{l}\text { Creat } \\
\text { atmo }\end{array}$ & $\begin{array}{l}\text { "I hope people can consider Dimerco as a company with a culture of nurturing. In the } \\
\text { process, many people started like a white piece of paper and developed to be professional } \\
\text { employee. People can influence the career pace here and they know the development. } \\
\text { Because of such a system, it is easier for them to be part of Dimerco." } \\
\text { "I would say innovation can be taught and encouraged. It is about incentives. We train our } \\
\text { employees' professional skills and management skills. We try to put the right person in } \\
\text { the right position through our position-switching system. We also have an open culture to } \\
\text { encourage people to be innovative." } \\
\text { (General manager, Headquarters) }\end{array}$ \\
\hline
\end{tabular}

